\title{
Hi-Tek Learning Strategies
}

Victor Selman, (E-mail: vselman@american.edu) KSB, The American University Jerry Selman, (E-mail: jeruhe@aol.com) Era, Inc.

\begin{abstract}
Unorthodox ways currently used in colleges to accelerate the velocity of learning are reviewed. To augment persuasion and articulation ability of business school students, stand-up comedy is used (University of Chicago). Song writing, storytelling and improvisation (VanderbiltUniversityOwens Management), and for Shakespearean motivation for other management skills at the corporate execu-tive level (Northrup Grumman). Food “chow-down”, before and during classes, including pizza and chocolate candy, for relaxation and memory stimulation. The aromatherapy path to the learning, the path of music and subliminal sound---Mozart effect and silent sound-and other sensory aids and teaching techniques to activate all the senses for learning-Key for three, but strive for five!. Other learning techniques include Selman's Universal Method (SUM) of breaking large problems into manageable parts or patches, his MEDICASA model and a platoon system of participatory responses---all demonstrating skills, motor and sensory. Another approach is to have abstract ideas in the sciences translated into physical learning aids, or robotic device, or toys----where the kernel of the analogies can be retained for comprehending different situations in the present, and for future metaphors. Learning can be reinforced in many ways. But learning without play is difficult---grim and boring presentations. It may be the major failing of our educational system; especially, as training for persuasive communication skills. This paper asks---What if it were possible to transfer information and improve communication without the circuitous paths of present ways of teaching? What if a teacher could guide a student beyond the normal capacity of his/her mind by "broad-casting" over the natural defense mechanism of the unused $90 \%$ of the brain?
\end{abstract}

Fun Is A Basic Genetic Instruction For All Higher Animals Because It Is The Way They Learn Humans Must Learn All Their Lives And Therefore Continue To Play And Look For Fun Well Into Old Age.

\section{Control Theory, Wm. Glasser, M.D.}

\section{Introduction}

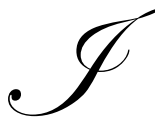

s Hi-Tel Learning, in its entire new concept, a scientific exploration, an artistic experience, or a seamless integration of science, art and the inner work of the human brain---overriding individual personality barriers? Words like "bribery," "sneaky learning," "tricky learning" have entered the scholastic workplace in the growing attempt to reach all students whether they have audio, visual, kinesthetic or other "wild" points of learning entry.

Models--simulation or devices-- cannot replace the real world; at best, they can reduce a complex system to manageable patches---becoming virtual educational innovations. At the recent Tokyo Toy Fair [1999], the MIT Media Laboratory's Toys of Tomorrow Project [which has sponsors including Warner Bros. and Intel] made their debut with Media Technology Professor Michael Hawley's comment--“Toys aren't just for playing around---they are tools that can help us turn our dreams into reality." But the idea behind the MIT Project is to use technology to create toys and devices that let users take more creative control; e.g., by programming a dancing robot, or composing music the popular Furby doll can speak 800 words and phrases, and has more computational power than the lunar exploratory module (LEM).

Readers with comments or questions are encouraged to contact the authors via email. 
We are unilingual in a multilingual Babel culture, without translators, with continually changing rules of grammar---a new "Esperanto" without an unabridged dictionary for the many ambiguous, core meanings embedded within our multi-cultural heritage, like words in the old Hawaiian dictionary.

An intriguing aspect about fun learning in the 21st Century is that we just do not have the time nor the capability nor the comic instincts to face the grim, unsolvable problems we have to learn to resolve today and tomorrow---to teach us something about ourselves and each other, and give everyone a laughing start to real learning. When we are both learning and having fun, long hours and hard work is tolerable---without fun, these tasks become drudgery. "Fun is such an integral part of our lives that most of us could not conceive of life without it," Glasser posits [8], "yet it can be as much in conflict with the other needs as they are with each other. It can be in conflict with survival, with belonging, with power. But when you have power, you also have more time for fun, so power can also be very supportive of this need. I believe that fun is the basic genetic instruction for all higher animals because it is the way they learn. Humans driven by complex psychological needs that are always in some conflict, must learn all their lives and therefore continue to play and look for fun well into old age. In fact, losing interest in looking for fun may be a sign of mental deterioration in older people."

American education, both as a learning system and a philosophy of learning--is in a state of great controversy, as we enter Millennia-3. Seen as archaic, medieval Wave-2 holdouts by many futurists and change agents, as little institutional reform is being made by the establishment to enter the digital Wave-3 world of accelerated SuperLearning. The concept of waves is metaphoric, trying to explain the hidden code of rules, or principles, repeatedly running through all the activities of each civilization. Inherent in the concept is the starting time of each wave, the crest time of each wave, the time window or period of complete duration, and the speed. All human experiences, basic perceptions, definitions of the good life, expectations for the future, and technological development are shaped by the social, political, and technological milieu in which they co-exist. Toffler's "First Wave" was agricultural civilization. The Second, industrial. The Third is the emerging structure grouped around the development, possession and transfer of high-tech knowledge---"software over steel." Future conflicts, Toffler states, will come because of the clash of these hierarchies in our trisected planet---e.g., as Wave-2 nations prepare to become Wave-3. "It has belatedly begun to dawn on people that industrial civilization is coming to an end... Today many use the term "postmodern' to describe whatever it is that comes after modernity [21]."

What most corporations want to see in their new-MBA hires is "someone who is articulate, persuasive and can read a balance sheet---in that order." Business schools have consistently turned out graduates who could read financial statements and do cabalistic statistical analysis--but that's all. Having students become "Jerry Seinfelds for a day gives them valuable communication skills and increased confidence. If my students can handle a stand-up comedy routine, they can handle anything [13].”

At the University of Chicago, Director/Actor Bret Scott of the Second City Acting Troupe was assigned to coach graduate business students to improvise comedy routines. And earlier last year at Vanderbilt University in Nashville, TN, a business student stood before his classmates and delivered a five-minute stand-up routine "laced with self-deprecating humor."

The executives of Northrop Grumman's Electronic Sensors and Systems Sector are studying the strategy of war and competition through Shakespeare's plays. A company called Movers and Shakespeare offers leadership training and impromptu costumed play-acting in "drive-by Shakespeare" retreats. "You can talk about the 12 great qualities of leadership and two hours later the students will not remember what was on the list. You've got to draw people into a story, and I'm convinced that's what they remember and not the principles," concluded Professor Useem, Wharton School, Center for Leadership and Change.

Simultaneously, there is much interest in promising alternatives and innovations in education, exhibiting possibilities for new curricula and new instructional patterns---as well as a sharp break with traditional forms of college pedagogical programming, to "trick" students to think for themselves, and to perform serious inquiry into the various disciplines [11]. But, unfortunately, there are no quick fixes for the agenda of educational reform---to learn better, faster and become a self-motivated, articulates person, with a passion to help others. 


\section{Communication Skills}

Quo Vadis? Science, Hi-Tek Science, is part of our new millennial culture, combining $21^{\text {st }}$ century physics with the inner realm of the child's imagination. Magical thinking "blurs the border between thinking and doing, between the inner space of imagination and the outer space of objectivity, confusing the volitional act of willing with causality, "states Dr. Leonard Shlain [19]. Children desire to engage in games that have as their goal a wondrous concept called fun---the outward manifestation of the internal state called "fun" is laughter, which Wyndham Lewis called "mind sneezing." Laughter is a unique behavior pattern fully developed only in Homo sapiens.

How can professional educators bring quality lessons to the children of the Millennium, where computers replace drill books and even textbooks, where primitive forms of artificial intelligence can diagnose learning deficiencies and tailor computer instruction to compensate? Where students are exposed to more information in one year than their grandparents encountered in their entire lives, and they will have to assimilate more inventions and more new information than have appeared in the last 150 years.

What can we as educators--teachers and professors--do about the new wave of digitalized students who grew up from age two with Playstation reality and MP3 music? Who have no history to fall back on if their machines break down, or to use other approaches---all dealing with effects, not root causes? We know that there is always another way to do anything---But do they? We are unilingual in a multilingual Babel culture, without translators, with continually changing rules of conduct and grammar---a new "Esperanto" without an unabridged dictionary for the many ambiguous, core meanings embedded within our multi-cultural heritage, like root words in the ancient Hawaiian dictionary.

Seen by futurists and change agents as archaic and medieval, Wave- 2 holdouts in institutional reform prevent the establishment from entering the digital Wave-3 world of accelerated Super-Learning. The concept of waves is metaphoric, trying to explain the hidden code of rules, or principles, repeatedly running through all the activities of each civilization. Inherent in the concept is the starting time of each wave, the crest time of each wave, the time window or period of complete duration, and the speed. All human experiences, basic perceptions, definitions of the good life, expectations for the future, and technological development are shaped by the social, political, and technological milieu in which they co-exist. Toffler's "First Wave" was agricul-tural civilization. The Second, industrial. The Third is the emerging structure grouped around the develop-ment, possession and transfer of high-tech knowledge---"software over steel." Future conflicts, Toffler states, will come because of the clash of these hierarchies in our trisected planet---e.g., as Wave-2 nations prepare to become Wave-3. "It has belatedly begun to dawn on people that industrial civilization is coming to an end... Today many use the term 'postmodern' to describe whatever it is that comes after modernity [23]."

New approaches to better communication skills have been tried at many universities for MBAs and other graduate students. Companies are also trying to improve the vision and leadership ability of their executives. Unorthodox ways used in colleges to augment persuasion and articulation ability in management schools is to use standup comedy (University of Chicago), song writing, storytelling and improvisation (Vanderbilt University at Owens Management Center), and for costumed Shakespearean acting to develop motivational management skills at the corporate executive level (Northrop Grumman) temporal vision [4].”

Taking a cue from what today's employees want, companies are using fun and flash to attract the best talent, and doing whatever it takes to keep them happy [13]. Employees of $i X L$, Inc. (a company that provides Internet consulting to Fortune 1000 companies) work in a fun-room atmosphere, taking breaks to play Sega video games, shoot pool or play Foosball. The company's meeting spots include a Japanese Garden Room with soothing ceiling to floor waterfall, with a whiteboard hidden behind a silk screen; a '70s Room with adult- sized beanbags, a Velcro wall, a beaded door curtain and flowered carpets illuminated by black light. Perks include "fully stocked fridges in the four kitchens, free soda fountains and coffee, gumball machines (you need your own change for these) and snacks." More and more we seem to be going back to the Montessori philosophy of "education of the senses," or the Lockean model of the mind, which can only be filled by exposure to sensory stimuli and orderly experiences--the recombining and modification of these simple ideas transformed by cognitive mechanisms into complex ideas. 
Basic problem-solving skills for decisions in the "real" world, using street smarts of common sense, are being cultivated in some classrooms. David Perkins, co-Director of Project Zero--a research group at the Harvard School of Education--states, "the world is not made up of well-defined problems. It is made up of complicated, messy, chaotic situations...for which we'd better have the skills to cope." Perkins $e t$ al have dubbed this coping ability "intelligence in the wild." Thinking "in the wild" means not just being able to solve a problem, but also recognizing that a problem exists in the first place, what that problem is and how much energy and effort should be invested in solving it. Common sense is a component of this kind of intelligence, but so are curiosity, openmindedness and sensitivity to one's surroundings. Perkins recommends that teachers ideally have students answer three types of questions---questions of exploration, conclusion and connection.

The future education sides are becoming more clearly defined: Either a continually modifiable contemporary system inputting necessary upgrades quickly and incrementally---or a "new" system so awesome and different that we cannot yet define its boundaries and scope, and future speculation becomes subjective, hopeful, full of stress and somewhat magical.

New approaches to better communication skills have been tried at many universities for MBAs and other graduate students. Companies are also trying to improve the vision and leadership ability of their executives. Unorthodox ways used in colleges to augment persuasion and articulation ability in management schools is to use standup comedy (University of Chicago), song writing, storytelling and improvisation (Vanderbilt University at Owens Management Center), and for costumed Shakespearean acting to develop motivational management skills at the corporate executive level (Northrup Grumman) temporal vision [4].”

As we are entering Millennium-3, we think of alternate futures---some with bad terminal outcomes, like man becoming the victim of his own hubris. In another, man learns to control those forces shaping his existence--conscious of the way he is creating the future, more conducive to his new cosmic awareness, than the present. "We are all futurists without knowing it. We all construct the future by everything we think, feel and do, but we tend to do it unconsciously, with limited spatial and informational capability." Mother Earth begat all the necessary sacred things needed to make the future.

More and more we seem to be going back to the Montessori philosophy of "education of the senses," or the Lockean model of the mind, which can only be filled by exposure to sensory stimuli and orderly experiences--the recombining and modification of these simple ideas transformed by cognitive mechanisms into complex ideas.

\section{Learning Aids and Devices---Redux}

Schools (and businesses) are struggling to find ways to educate and motivate their students (and mployees) on various subjects, including persuasion, and the new digital technologies. Teacher-led instructor-led training is expensive and difficult to work out logistically. Interactive, contextual learning is required that is fast, multimedia based and stimulating. The Internet for schools (or company's intranets) may become the future generic medium for teaching, lecturing and demonstrating incremental yet continuing training. Learning aids, toys, robotic devices and simulation techniques will be explored for state-of- the-art reinforcement of ideas and innovative concepts at this point in time.

One way to reinforce concepts--tactical as well as OR-type strategic problems---is to devise "hands-on" simulations and/or appropriate analogies. Models are classified in terms of the system being modeled; such as, continuous versus discrete, deterministic versus stochastic, physical versus mathematical. A further distinction is made between static and dynamic models. For mathematics, the split is between analytical and numerical models, analog and digital. Management games, workshops, retreats and/or training exercises illustrate the complex relation-ship between decision- making processes and new information technology and knowledge systems. Models are neither true nor false; their value is judged by the contribution they make to our understanding of the system or concept they represent [8].

The following anecdotes, robotic devices, illustrations and exciting innovations relating to play learning 
encompass the first steps in attempting to change the mindset of educators operating under the present traditional educational paradigm---by first loosening the Rules of the Game. As the late Thomas S. Kuhn has delineated in his seminal key book, Concepts for The Structure of Scientific Revolution, scientific progress is not necessarily a gradual linear process---usually, it proceeds in four stages, of which the last phase is seen as a total break with the cumulative tradition that preceded it.

Educators at various levels have explored the use of learning aids and simulation techniques: Escalante (Garfield High School) uses a wind-up walking-shoes toy for a step-by-step approach to algebra, and a plastic monkey climbing up and down a small pole to illustrate the inverse function--exchanging y for $\underline{\mathbf{x}}$; Dr. David Carson (Rensselaer Polytechnic Institute) creates a level playing field for science and humanity majors using Tinker toy blocks for his courses in technical writing and editing; Marva Collins (Chicago Westside Preparatory School) uses a number of original learning aids; Deirdre Donovan (Transit Tech, NY) uses visual play-cartoons, art prints, movie clips-to win "Special Education" converts to Shakespeare [20]; Dr. Victor Selman (The American University) uses a multiplicity of original and modified high-tech toys and simulated robotic models to reinforce management concepts and OR-applications, enhancing their absorption in business management and production. Selman will demonstrate his basic MEDICASA Model for business usage---Measurement, Efficacy, Data Development, Imagery and Integration, Computerization, Analysis, Sensitivity, and Applicability to Objective. Appendix A, Selman's MEDICASA Model, fleshes out and clarifies the mnemonic metaphor, permitting easy discovery of the kernel of wisdom inside each abstraction. Maria Galvez-Martin (Ohio State at Lima) focuses on the importance of teaching Social Studies with toys through play [7], as a hands-on approach for in-service teachers with role-playing and journal recording in a course "Teaching with Toys." Play is an essential learning tool because it develops thinking (both internal speech and abstract thought), language, creativity, memory, motor and mental skills such as problem solving, (decision making), while supporting the socialization process of learning how to learn.

Another area worth mentioning is the body of research of the experimental psychologist Dr. Neal E. Miller, with regard to his discovery of "visceral learning" and the biofeedback mechanism, considering the Zen and Yoga approaches to the bodily phenomenon---breathing, blood pressure, sweating. Miller explores the possibilities that man can train and control not only his mind and the skeletal muscles, but also the deepest visceral processes. "In a paradox worthy of the ancient Zen masters, biofeedback researchers have discovered that living organisms can modify many supposedly involuntary bodily functions if they are guided by external signals that tell them what is happening inside their bodies from moment to moment [8]."

When it comes to interpreting this discovery, scientists tend to divide into two camps: one group, drawing on communications theory, stresses the purely informational aspect of the feedback signals; the other group, drawing on behaviorist learning theory, stresses the role of the feedback signals in reinforcing appropriate responses [10]."

The basic principle of biofeedback training is perfectly compatible with the Western emphasis on achieving mastery over the external conditions of life: If you know the results of your past performance, you can improve your future performance. Parents and teachers apply this principle to their everyday life without thinking about it--a mixture of tentative knowledge and speculation. Union High School in Sacramento, California, has been using biofeedback gadgetry to reduce student stress

Toys simultaneously involve both teachers and students in the fun and mental aspects of science. In summary, if toys are used in an inquiry manner-analyzed both qualitatively and quantitatively--, they can be used interactively to discover scientific principles and discover scientific process skills [15].

Current models--simulation or robotic devices-- cannot replace the real world; at best, they can reduce a complex system to manageable patches---becoming virtual educational innovations. At the recent Tokyo Toy Fair [1999], the MIT Media Laboratory's Toys of Tomorrow Project [which has sponsors including Warner Bros. and Intel, and partnership with Hasbro, Mattel, Walt Disney and Lego] made their debut with Media Technology Professor Michael Hawley's comment--“Toys aren't just for playing around---they are tools that can help us turn our dreams into reality." But the idea behind the MIT Project is to use technology to create toys and devices that let users take more creative control; e.g., by programming a dancing robot, or composing music. Mitchel Resnick, a professor of 
research in education for the MIT Project, in his "play-area" workshop is re-designing toys for children of the digital age, which he hopes will help them learn better as they prepare for an increasingly computerized world--including high-tech computerized Lego blocks with two sensors controlling two motors [as powerful as the once popular Apple II computer series], intelligent "smart" beads with tiny colored lights and sensors that can be programmed to communicate with neighboring beads and light up under certain conditions, and kits that allow children to design their own scientific instruments. Children can use desktop computers to write instructions for the blocks in a simple programming language called LOGO; then, using infrared signals instructions can be beamed to specific computerized blocks in a model. There will be a much larger electronic and computational component to the toys of tomorrow, Resnick predicts.

And the Lego System? Just when you thought the old LEGO (<www.lego.com>) blocks were so 1980-ish, the Danish pros come up with the ultimate toy---LEGO Studios Steven Spielberg MovieMaker Set, with PC video camera and video-editing software from Pinnacle, which with 400 Lego blocks and a mini Steven lets you build scenes and direct robots on a cool movie set right out of the Star Wars series, dub a soundtrack and edit your movie or e-mail it. The kit (\$179.99) includes actual blocks, wires, special effects gizmos, etcetera, for building even those humpback robot creatures (ATAT Walkers) from The Empire Strikes Back. An optional kit called Explosion Studios lets you actually film an explosive action scene (\$35). (See <www.lego.com/studios>.)

Can the trademarked plastic building blocks from Lego determine strong college candidates? Can the blocks replace SAT scores or grades? Can it identify leadership, conflict negotiation and effective communication skills? Corporate communities nation-wide have discovered the blocks as a means to identify characteristics necessary for top employees, says LEGO executive Michael Seabury [6].

Lego does use the blocks only for human resource leadership exercises, according to the Lego Group in Denmark. At Harley-Davidson and Toyota, all new employees use LEGO blocks to sharpen their problem-solving skills. Maytag is among companies that offer "mind kitchens" that include the blocks as creativity-stimulating objects. Some others, including Zefer, an Internet solutions firm in Boston, use the blocks to screen job applicants [24]. Scoffers of the Lego System, including Rush Limbaugh, argue against replacing today's objective standards with what they consider subjective decisions. At Florida Atlantic University (FAU), Boca Raton, budding electrical engineers design LEGO Robots for robot races in Professor Daniel Raviv's inventive problem-solving class. And the latest is a theme park [LEGOLAND, in Carlsbad, CA] made by LEGO with 30 million Lego pieces-about 15\% of all the Lego pieces in the world-for children ages 2 to 12 with 40 hands-on attractions and rides, most requiring some kid-power to work

A new company RocketPod (from NextPlanet) has designed a suite of MP3 players (\$300), camcorders, DVD players---stackable sandwich-sized "pods" that run on a single operating system--without any fussing with software--, with a single USB hub (\$50) doubling as a power source, linking the devices to your PC. "It is kind of like a Lego set, "CEO David Roth says. "It's up to the user to come up with new ways of putting it together."

At present, many computerized toys are already on the market. Although not quite R2D2, robotic devices are coming to market on their own battery power, providing household tasks, from cutting the lawn to floor cleaning, to baby watching. The most sophisticated helper is iRobot-LE $(\$ 4 \mathrm{~K}-\$ 5 \mathrm{~K})$, with a LINUX operating system, together with its unique wheel system, lets it climb stairs <www.irobot.com>. From Israel's Friendly Robotics RL500 (\$795) comes their new Second generation robotic lawnmower, which misses all obstacles <www.friendlyrobotics.com>. A solar powered lawn maintenance system will be introduced in spring 2001 by Husqvarna $(\$ 2,500-\$ 3,000)$, which now makes the battery-powered Auto Mower $(\$ 2 \mathrm{~K})<w w w . h u s q v a r n a . c o m>$. Eureka's prototype robotic vacuum for 2001, includes navigational sonar $(\$ 1 \mathrm{~K})<w w w . e u r e k a . c o m>$. A British version of a robotic vac by Dyson Appliances, DC06 $(\$ 3,500)$, includes three computers and "more sensors than the Mars lander," stopping itself at the top of stairs $<$ www.dyson.com>. Cye from Pittsburgh Probotics ( $\$ 700$ plus attachments) not only vacuums but serves drinks, and takes dishes back to the kitchen as well. A desktop computer provides the brain-power to communicate with Cye via a wireless link <www.probotics.com>.

More toy-like, Tamagotchi, a "virtual" egg pet [by Japanese toy maker Bandal] with its key chain-sized 
computer display, allows the user to feed, clean, and entertain the digital companion, which now has come out in a CD game for computers. Mattel has released a Talk-with-me-Barbie, which can be programmed to speak, remember a child's name, birthday and other information. Tiger Electronic's popular Furby doll can speak 800 words and phrases, and has more computational power than the lunar exploratory module (LEM).

Toys simultaneously involve both teachers and students in the fun and mental aspects of science. In summary, if toys are used in an inquiry manner-analyzed both qualitatively and quantitatively--, they can be used interactively to re-discover scientific principles and discover scientific process skills [15]. The National Rube Goldberg Machine Contests, conducted by Theta Tau Fraternity of Purdue University, are also noted, where any team of college students that has won a local contest can enter the yearly national robotic contest. The task for the 2001 contest is to select, clean and peel an apple in 20 or more steps (shades of Johnny Appleseed, to whom this task is meant as a tribute). Each year the task varies ---like developing machines to adhere a stamp on an envelope (1988), screw a light bulb into a socket (1993), insert and then play a CD Disk (1997), shut off an alarm clock (1998), set a golf tee and tee up a golf ball (1999)---all in twenty or more steps. In 1997 students from seven universities built on purpose a machine to make a computer more difficult to operate. [Rube Goldberg was a cartoonist who specialized in drawing whimsical machines with complex mechanisms to perform simple minimal tasks with maximal effort.] Machines are judged on the creative use of materials and use of related themes. Each machine must run, be reset and run again in nine minutes. Points are taken off for human intervention after the machine starts or for exceeding the time limit. The concept of a Rube Goldberg machine is "an excellent educational tool," according to the Contest literature.

Elementary schools are supplying students with original $\$ 100$ Sony Play-Stations, including joysticks and educational CDs of free video games that sneak in learning lessons in a way that contemporary kids can appreciate. UCLA Professor Gordon Berry says that the new PlayStation Program is part of a national trend--- instead of competing with TV and video games for the attention of their students; schools are using them to capture it. A California-based software company called Lightspan, which has Berry as their adviser, provides math, reading and writing lessons so cleverly formatted that children do not think they are doing math-Goggle Math--they think they are playing games. The games also allow students to work at their own pace, extending the classroom into their homes, and getting their parents, grandparents and siblings involved [6]. Did you try to buy Sony's new \$299 multimedia PlayStation 2 (PS2) videogame console (accompanied by 26 new games with amazing graphics, wireless remote for the DVD, and compatible peripheral digital camera and printer)? This was the IT Toy for Christmas 2000--just like the previous Cabbage Patch Kids, Beanie Babies and Furbys--, and almost as impossible to get--CEO Ken Kutarangi sympathetically told Newsweek that Sony is shipping an additional $100 \mathrm{~K}$ machines every week, asking that "consumers be patient just a little while longer, if they can't get one right away!"! Good luck! [Classified pre-holiday newspaper ads were asking $\$ 550$ to $\$ 1,000$ for boxed PS2s!]

"Everybody loves toys. Some of us just pretend that we are too grown-up for them, but the truth is that most adults are just closeted children," says Yael Li-Ron in "Ready for the Future" in the 30 October 2000 issue of Newsweek magazine [13]. For those of us who enjoy the company of dogs and/or other nonhumans, there's AIBO ERS-210 ( $\$ 1,590$ with software package), the Second Generation virtual Artificial Intelligent Robot toy-poodlesized dog from Sony (<www.sel.sony.com>) with 20 motorized joints, flapping ears and wagging tail, who comes house-broken, able to learn about fifty verbal commands and mature like a living creature, expressing six different emotions: happiness, sadness, anger, fear surprise and dislike. AIBO is obedient, responds to praise and happiness when its needs are met, does not have to be walked and will listen to your troubles, without telling you that you have bad ketonic breath; incidentally, "aibo" in Japanese means "companion." AIBO has most of the senses a selfrespecting dog would need--touch, hearing and seeing (it has a small camera in its nose)--and does tricks (sit, roll over, plays with pink ball, also included) like it has free will. "Sony feels like the way to launch the robot revolution is through entertainment, so it plans to release a slew of electronic critters over the next five years [13]." By 2005, Sony hopes to release a line of electronic acrobats that have the ability to jump, dance around and even kick a small soccer ball.

At the low-dollar end of the spectrum there is Rocket the Wonder Dog by Fisher-Price (\$100) who rolls his eyes among other tricks, responds to commands spoken via headset (included) <www.fisher-price.com/us/rocket>, 
yet does not stain the carpet; Robo Pup (\$50), a teacup-poddle-sized pet that shows when it is happy/sad/angry with its sensors (head, light, mouth, sonic), sings and barks as a watchdog; Tiger Electronics' Poo-Chi Pup $(\$ 30)$ or RoboChi 102 Dalmatians, who do a few tricks and even interact with Super Poo-Chi (\$50), who has voice recognition technology to respond to owner's commands; Big \& Lil' Scratch (\$65), a "lovable pair" who act and move like real dogs, controlled by a key-chain remote; Wow Wee, iMega-Byte, the interactive Hound Droid (\$25) in three wild colors; Tekno's Robotic Puppy or Dalmatian Puppy with artificial intelligence-walks, talks, barks, sings, dances and plays card tricks with his animated eyes, ears and wagging tail (\$45), <www.tekno-robot.com>; and the electronic talking Scooby Doo (\$22). Then there are the interactive intelligent robots from another planet in 59 collectible colors ---the RoboNagis (\$50), <www.robonagi.com>, programmed to grow and change with their individual personalities, to learn sensitivity and responsibility, as they are fed and loved. Also Buster the Robot $(\$ 100)$, a remotecontrolled robot with built-in flashlight, working arms, and voice-transmitting technology; and M.A.X. (Mechanized Android Xplorer), a 30-inch radio-controlled robot from Robotix (\$100), powered by three independent motors--with detailed instructions for building.

\section{Robo sapiens}

The science of Robotics has been called the marriage of man and machine, or computer and machine. The late Isaac Asimov's Three Laws of Robotics [from the Human POV] states that robots can protect themselves as long as they don't disobey or harm people. According to some computer scientists, the definition of functioning in the "real World" is also changing. They believe that cyberspace and artificial reality are as real as the physical world. If the electronic world is "real," than robot controller brains could contain the computer programs of artificial life behaving like living organisms---mating (interacting with other programs), reproducing (creating new programs), passing on characteristics according to the rules of genetics, competing with other programs, and evolving into very different programs. Ellen Thro [22] states: "Some artificial life programs use computer graphics to draw pictures of the creatures. Each new generation appears on the screen, showing new characteristics and mutations. Some of them even evolve into different species. They become predators and prey. Some species become dominant; others die out. Some scientists say these organisms are very close to being alive. They fit the biological definition of life, erasing gradually the line between living organisms and non-living matter."

Recently, at the Comedy Central's Battlebots competition in Las Vegas, Tonight Show host Jay Leno created the strategy for his robot "Chin-Killa" [to ram the other guy], and easily won over "Ginsu," a combination of saw blades on wheels. About 140 robots entered the competition, where pairs fight three-minute duels inside a Plexiglas-enclosed ring until one is destroyed or badly damaged. Before the actual fight, Leno had "Chin-Killa" destroy a mock Florida ballot-counting machine [14]. Sumo wrestling with robots is growing in popularity---not just for children. At the San Francisco Exploratorium, challengers fight unsuccessfully against Japanese. Sumo robots. According to the International Federation of Robotics (Sweden) there will be nearly 900,000 robots of all types installed around the world by 2003. In 1995, there were 615,000, mostly in Japan, welding cars, assembling electronics and constructing other robots.

At the American International Toy Fair in February 2001, the next generation of electronic pets was previewed---they will tell jokes, sing round-robin with their robotic friends, and wake you up when and if you want. Hasbro Inc. 's Tiger Electronic now has robots ranging from Ottobot, a wise-cracking robot with a 200-word vocabulary and built-in games to T-Bot with 60 different facial expressions. In May 2001, I-Cybie (\$200), will be offered---a fully motorized talking dog that knows when its batteries are low and will follow an infrared beam back into its recharging base and plug itself in. Trendmasters Inc. will produce three new robotic brands this year, according to its VP for Creative Development Brian Weinstock: It's Johnny Bot series will sport different personalities, tell jokes and recognize people in a room; Rumble Robots will fight, gaining power through electronic cards; C-Pets has am array of various animal models, including a 12-inch wise-cracking lizard, that plays gamers and dances. Manley Toy Quest (producer of Tekno-Pup, 1999-2000) will offer an upgraded sophisticated trio of lifelike 16-inch exotic birds (\$70 each) which can sing in round-robin style, wake you up at programmed times, or follow you with their heads as you walk across the room. The new Intel Play Computer Sound Morpher (\$50) with its text-to-sound features encourages children to interact with their home PC. Using the battery-powered mike sounds around the house can be recorded - a dog barking, a parent talking - then downloaded through an USB port for manipulation; 
making the voices sound like robots or monsters---even changing the word order of recorded sentences. (See <www.intelplay.com>)

Starting Summer 2001, an interactive 6-foot-tall robot designed by Mobot, Inc. designated as "Adam 4080" will interact with travelers passing through Pittsburgh International Airport, roaming the airline hub at the escalators that link the four concourses, offering information ranging from flight schedules to Pittsburgh's coming attractions. Mobot's robots are already stationed at the Carnegie Museum of Natural History and the Sen. John Heinz Pittsburgh Regional History Museum. NEC's personal 15-inch robot is a step up in sophistication with 5 sensors, recognizing up to 650 phrases, speaking more than 3,000 words, dancing, alerting you of e-mail and home security.

When Al Gross (a.k.a. Phineas Thaddeus Veeblefetzer) passed away at the end of the last millennium, the gizmos he designed and patented --just $f$ or the fun of it!-- like Dick Tracy's two-way mobile wrist radio, the walkietalkie, and other wireless wonders have a revered resting place in the heart of our fun memories. New millennium watches now let you snap pictures and check e-mail! Casio's Wrist Camera $(\$ 200)$ will beam your black and white stamp-sized pictures to similarly outfitted friends, or with the optional infrared adapter $(\$ 50)$, upload them to your computer. Heart-rate monitors strap around your rib cage and continuously transmit to the Polar S210 wristwatch (\$200) receiver. Casio's PC Unite $(\$ 105)$ synchronizes with popular organizers to store up to six phone numbers and one e-mail address for up to 100 contacts. Casio's GPS Satellite NAVI (\$500) uses data from up to 12 globalpositioning system satellites to figure out your exact latitude and longitude. It keeps track of where you've been, plotting your progress on the screen to help you retrace your steps should you lose your way sailing or hiking. It comes with a useful cradle that both lets you recharge the battery and link the watch to your computer for importing maps and route plans. The new Timex Internet Messenger (\$99) is a state-of-the-art pager watch that can receive auction alerts from eBay, or short e-mails from your broker. Other watches take your blood pressure or change the channel on your TV!

Incidentally, Kyocera's Smartphone (est. \$400-500) is one of the new hybrid gadgets, (<kyocera.wireless.com>) that works as a cell phone with the flip closed, and as a Palm-compatible PDA (personal digital assistant) with it open. Others combine such organizer gizmos as calendars, address books, and to-do lists, as well as capability for handling e-mail, Web surfing and your ordinary voice calls.

Dr. William Glasser writes in Control Theory that "Fun is a basic genetic instruction for all higher animals because it is the way they learn...humans must learn all their lives and therefore continue to play and look for fun well into old age." An intriguing aspect about fun learning in the 21st Century is that we just do not have the time or the capability or the comic instincts to face the grim, unsolvable problems we have to learn to resolve today and tomorrow---to teach us something about ourselves and each other, and give everyone a laughing start to real learning. When we are both learning and having fun, long hours and hard work is tolerable---without fun, these tasks become drudgery. "Fun is such an integral part of our lives that most of us could not conceive of life without it," Glasser posits [8], "yet it can be as much in conflict with the other needs as they are with each other. It can be in conflict with survival, with belonging, with power. But when you have power, you also have more time for fun, so power can also be very supportive of this need. I believe that fun is the basic genetic instruction for all higher animals because it is the way they learn. Humans driven by complex psychological needs that are always in some conflict must learn all their lives and therefore continue to play and look for fun well into old age. In fact, losing interest in looking for fun may be a sign of mental deterioration in older people."

American education, both as a learning system and a philosophy of learning-- is in a state of great controversy, as we enter Millennium-3. At the Comdex trade show [Fall, 2000], Microsoft Chairman Bill Gates III showed off his projected wireless-tablet computer, which can be hung on your refrigerator door or plopped on your lap in your working area, where it can help you with Web browsing---even turn on your house alarm system, brew the coffee and read your e-mail. SONICblue (formerly S3) has developed the Frontpath Progear <www.frontpath.com> based on a Transmeta processor with the Linux operating system and a Netscape browser, is targeting schools in partnership with River Logic which supplies software. A light, wireless and relatively inexpensive tablet seems ideally suited to educational use, as it makes information available in any corner of your house, from couch to kitchen. One model available today is the Honeywell WebPAD, a 3-pound tablet with a 10.4-inch 
display, <www.honeywell.com/your home/>, designed to handle security alarms, heating and cooling systems and other household-control applications ( $\$ 995$, without the $\$ 195$ wireless-base station). The next version will have a better display and industry-standard 802.11 wireless technology, in place of the proprietary Proxim Symphony system used now.

One way to reinforce concepts--tactical as well as OR-type strategic problems---is to devise "hands-on" simulations and/or appropriate analogies. Models are classified in terms of the system being modeled; such as, continuous versus discrete, deterministic versus stochastic, physical versus mathematical. A further distinction is made between static and dynamic models. For mathematics, the split is between analytical and numerical models, analog and digital. Management games, workshops, retreats and/or training exercises illustrate the complex relation-ship between decision- making processes and new information technology and knowledge systems. Models are neither true nor false; their value is judged by the contribution they make to our understanding of the system or concept they represent [6].

Researchers at the MIT Artificial Intelligence Lab are developing social robots that have the ability to respond to and learn from subtle human interactions [13]. Rodney Brooks who heads the Lab is also chairman of iRobot Corporation [My Real Baby robot] plans on releasing a robotic dinosaur, the Veloceraptor, in Fall 2001. The iRobot-C due early in 2002 (www.iRobot.com) can serve as remote eyes and ears, can be placed anywhere in the world and be controlled by a Web Browser $(\$ 2 \mathrm{~K})$. Brooks is betting that one day soon robots will take off like PCs have. He's relying on toys to make this happen. Kismet with big blue eyes and a sweet red mouth, driven by 15 computers with AI programs is learning social behavior with the help of a caregiver. The notion was to create robots designed to show emotions. Cog, another MIT robot is an experimental humanoid replica, incorporating humanlike senses into mechanical beings, so that robots will make better roommates in the future. But true androids of the R2D2- variety that can think for itself and handle unfamiliar situations and environments are still down the road.

Professor Jerry Haky and his colleagues of the Chemistry Department and education school of Florida Atlantic University (FAU) at Boca Raton recently won a grant to promote their program Project ChemBOND---which has reduced the failure and withdrawal rate of general chemistry students from $48 \%$ to $20 \%$ in two years, while tripling class enrollments. To demystify chemistry FAU is teaching basic concepts rather than formulas using everyday objects like balsa wood airplanes - which students assemble like molecules--and sweet tea, to study molecular structure and stoichiometry, keeping more focused on the concepts, while they work in small groups in weekly sessions, guided by upperclassmen, to supplement the lectures and traditional labs. FAU's new approach is "on the leading edge of a national effort to retool chemistry education." At the University of Central Florida, where the first-year failure rate is $30-40 \%$, professors are making lectures more interactive and rewriting lab manuals.

Another area is the body of research of the experimental psychologist Dr. Neal E. Miller, with regard to his discovery of "visceral learning" and the biofeedback mechanism. Considering the Zen and Yoga approaches to the bodily phenomenon---breathing, blood pressure, sweating, Miller explores the possibilities that man can train and control not only his mind and the skeletal muscles, but also the deepest visceral processes. "In a paradox worthy of the ancient Zen masters, biofeedback researchers have discovered that living organisms can modify many supposedly involuntary bodily functions if they are guided by external signals that tell them what is happening inside their bodies from moment to moment [10]." When it comes to interpreting this discovery, scientists tend to divide into two camps: one group, drawing on communications theory, stresses the purely informational aspect of the feedback signals; the other group, drawing on behaviorist learning theory, stresses the role of the feedback signals in reinforcing appropriate responses [16]."

The basic principle of biofeedback training is perfectly compatible with the Western emphasis on achieving mastery over the external conditions of life: If you know the results of your past performance, you can improve your future performance. Parents and teachers apply this principle to their everyday life without thinking about it--a mixture of tentative knowledge and speculation. Union High School in Sacramento, California, has been using biofeedback gadgetry to reduce student stress 


\section{Suggestopedia, Sophrology, Audio-Psychophonology}

The goal cited supra is exactly what Dr. Georgi Lazanov believes he has created---a teaching method that speeds up learning 50 times, increases retention, requires virtually no effort on the part of the student, reaches retarded and brilliant students alike, and requires no special equipment. "You can lean back, relax, listen to music, and learn without effort and without realizing it. The possibilities of using Suggestopedia on a mass scale are very promising [14]." At the Bulgarian Institute of Suggestology and Parapsychology, records of controlled tests reveal that hundreds of people from all levels of society learned entire two-year language courses in as little as twenty (20) days. Small experimental groups mastered courses in basic mathematics, physics, chemistry and biology in a matter of weeks! It is not hypnosis or sleep learning. It is far more practical than that. The student is fully awake and in complete control of himself, says Dr. Lazanov. It is a kind of mind contact between teacher and student, based on the Yoga technique of relaxation known as Savasanna. Using suggestion and auto-suggestion, muscle tension is relaxed and the brain is relieved of the usual activities and stresses. In this relaxed free state of consciousness or meditative state, fatigue quickly vanishes. Freed from all distractions which hamper its functioning, the brain resembles a sponge able to absorb knowledge of all kinds. "The possibilities of using Suggestopedia on a mass scale are very promising, "says Lazanov, adding, "It is inexpensive and ideally exportable [2]."

Bancroft in her persistence investigation of the Lazanov Language Method found out that the opening 74beat music was slowed down to 60-beat music with precision data pacing on an eight-second cycle. She concluded that this must be part of the acoustical breakthrough that mobilizes the subconscious, harmonizes right and left brain, relaxes the body and alerts the mind and expands memory [2]. Slow Baroque music is the link to the subconscious. Also, the up-tempo high-frequency music [Mozart] serves as a backdrop to the dramatic reading of learning material, gives an energy boost to the cerebral cortex to help charge up and rebalance brain and body. After listening to high-frequency music for a certain time, research shows that the brain seemed to become harmonized, energized and sharpened---giving out the right signals to the rest of the system to re-vitalize the whole self.

The secret of this technique is that material does not reach the memory in the ordinary way, because the student does not participate consciously in the process [2]. With basic knowledge quickly and painlessly instilled, schools could increasingly become places of creative teaching and thinking. During the time the teacher intones words against a musical background, there seems to be distinct physiological changes in the body and changed brain control of alpha waves, putting a predominately rhythm of rest in the brain. Once the mind is opened in this reverielike state, Lazanov found that the capacity to remember seems almost boundless-there is no apparent cutoff point. It is as easy to remember a hundred words than fifty [18]! Appendix B, demonstrates A Typical Lazanov Learning Exercise. In the West, UNESCO and the Ford Foundation had expressed interest in the Lazanov approach, and the New York State Medical College had invited Dr. Lazanov to speak there [1969]. The senior author met Dr. Lazanov in New York City prior to his United Nations' visit, and was impressed by Lazanov's multi-media presentation and the need for and potential of his rapid learning technique. Consensus at the time was quite positive [16]---that Lazanov's Suggestopedia was a genuine form of mind expansion. It is revolutionary---evolutionary, perhaps. Speculation was awesome---What powers, what talents will surge into being as more of the mind is freed?

Like Dr. Lazanov, Dr. Lozano Caycedo, also a medical doctor, at the University of Madrid, investigated techniques that permit a person to modify states of consciousness and thus act on the body/mind linkage. Founding the Centre of Sophrology in 1960 in Barcelona, he initially used sophrology medically in many areas, including gastroenterology, psychiatry, and obstetrics. Caycedo says. "We teach people how to breathe properly, how to anesthetize themselves and how to relax. We reinforce in a person his capacity to take charge, and thus his capacity for hope." From medicine, Sophrology moved to sports and education, where Caycedo observed that people developed hypermnesia--or super-memory-through Japanese Zen (which he considers a "perfection of Raja Yoga") and his own "dynamic relaxation" technique [3]."

Caycedo's system also used visualization exercises to achieve synchronization of body/mind rhythms, and sounds--not an orchestra like Lazanov--but by the human voice, "Left brain and right brain are stimulated globally by having the course material read almost in a singing way with special rhythms and intonation. This technique he calls terpnos logos, and it goes back to the ancient Greeks. [Plato described it as a special tone of voice---a soft, 
soothing, monoton-ous, melodious tone somewhat like an incantation.] Sophrology teachers are even given voice coaching along the lines of an actor or singer [3]."

Like Lazanov's Suggestology, Caycedo's Sophrology brings not only learning, but therapeutic spin-off benefits---improved self-confidence, improved creativity, improved emotional development and self-expression, and freedom of limited ideas about capabilities. A comparison of the work of both Dr. Caycedo and Lazanov has been made by Bancroft [3].

The Sound Therapy work of Dr. Alfred Tomatis (Toma-teece), the Paris E.N.T. specialist who believes that "listening is the road to learning," as he works to restore the full physical response of the ear as well as the person's emotional receptivity to sound. High-frequency music has been documented to help overcome a wide range of learning disorders and related behavior problems, as well as dyslexia, attention deficit disorder, hyperactivity, autism, and Down's syndrome---also in stuttering, hearing problems, vertigo and tinnitus, insomnia.

"The Ear is not made only for hearing---the ear is designed to energize the brain and body [17]." The modus operandi is that energy comes through the ears; Tomatis tracked Bach, Mozart, Gregorian chants and the singing of $O M$ on his instruments, observing that the debilitating effects of stress come when the central gray nuclei brain cells run low on electrical potential, like rechargeable batteries, generating the brain's electricity, powering the brainwaves showing up on the EEG. "Not so," Tomatis says. Through the ear you can tap into the vast, natural supply of cosmic energy---which never has shortages. And that is where a major breakthrough occurs. The Electronic Ear, a device invented and patented by Tomatis, emits bursts of varied high/low frequency sounds, alternating from ear to ear and forcing the middleman muscles to shape up. Once they do, the inner ear is "opened" and high frequency hearing is restored. An "open ear" is the Open Sesame for power learning, as well as the key to turning around widespread, ever increasing, learning disabilities. Sounds from 5,000 to 8,000 Hertz recharge "brainbatteries" most rapidly. The music richest in these ultrahigh frequency recharging sounds is Mozart. "Something outside of you charges up your battery cells and this something is sound, particularly high-frequency sound. The middlemen are your remarkable Corti cells. Arranged in rows, 24,600 long-stemmed cells dance in perfect precision to each sound, much like the Rockettes of Radio City Music Hall. The energy produced by this extraordinary dance flows to your brain and some of it also spills off through the vestibular branch of your auditory nerve and flashes to the muscles of your body. High frequency sound energizes your brain while at the same time, it releases muscle tension and balances the body in many other ways, even affecting your posture.

“Tomatis states that you don't get the jolt of energy if you can't hear the high frequency sounds. One reason we start to feel worn out as we get older is that we can no longer hear the higher pitched sounds that could reenergize us [17]. Tomatis also pinpointed frequencies that deplete mind/body: low frequency sounds, such as noise from traffic, airports, construction sites, also the low pounding sounds in rock music.

\section{Summary}

A "hands-on" fun workshop (with many original learning aids and robots) will be presented by Dr. Victor Selman, including a discussion/demonstration of his comprehensive MEDICASA Model for developing appropriate learning aids for various business subjects---quality control, linear programming, queuing, reliability, inventory theory, simulations (Monte Carlo), work measurements, etc. Learning aids are offered as the support metaphors in learning the complex concepts inherent in the real-life environment needed to go from traditional rote learning to actual deep "visceral" fun learning. Models cannot replace the real world; at best, they can reduce a complex system to manageable patches---serving to modify perception and concretize knowledge, becoming virtual real-world science innovations, without all the scientific jargon newspeak [14].

Fun-Learning aids are offered as the support structure in learning the complex concepts inherent in the real-life environment needed to go from traditional rote learning to actual deep "visceral" learning through the entertainment arts. Navigating around techniques of differing assumptions through the Scylla and Charybdis, we boldly steer toward new fun ideas and innovative methods that can enhance education and learning today, and for the fuzzy, yet super-serious millennial venues. Techniques presented are intended to enlighten, expand and change the 
learning eco-environment---helping to reduce the stress and other anxieties of the new digital Wave-3 world---in other words to try to figure out how best to change dated teaching styles to meet the velocity of the new learning milieu.

The serendipitous benefit is that the combined use of multiple senses and multiple intelligences, the creativity of the entertainment arts, the simulation concept, the audio-visual approaches that can be used in all disciplines--providing needed, rapid meta-fun learning techniques for the accelerating 21st Century venues. Oddly enough, the use of "sacred" sound in the form of repetitions, mantras, zikrs, and affirmations go far back, historically, to ancient neuro-physiological powers of chanting to reorganize the nervous system, and center consciousness---providing pathways to real learning by the deeper self.

We must not lose sight of the goal---to motivate educational learning to the MAX, whatever the individual's primary styles of learning is--audio-visual, tactile, kinesthetic--and focus on whatever sense is paramount to each individual's learning. The obverse side of the coin is that the current philosophy of learning must change, both in perception and assumptions---instead of thinking or using trial-and-error approaches for Eureka-type solutions, the new paradigm of the art of Hi-Tek learning is that game-like devices are programmed to offer suggestions for their own survival or comfort, interacting as they convert the essential data into a "new" body of eclectic learning. Imagine a ten-year-old Taiwanese girl going to an American secondary school and having a culture shock in permissiveness and disrespect for pedagogic authority. What should a teacher's job morph into? A Webmaster, advisor, electronics repair technician, game master, educational psychologist, referee? Techniques that could break through the barrier in the mind that prevents using the major moiety of our intellectual capabilities would be revolutionary.

We have opened up several areas of discoveries, speculation and inventions that have been at the fringes of the educational establishment for varying lengths of time. Some may develop into vital approaches to millennial teaching of our digitized students. Learning can be reinforced in many ways. But learning without play is difficult--grim and boring presentations it may be one of the major failing of our educational system; especially, as training for persuasive communication skills. Humor is the secret strategic weapon!

The serendipitous benefit is that the use of the entertainment arts, the simulation concept and the audiovisual approaches of suggestology/sophrology/visceral learning can be used in all disciplines---providing needed, rapid meta-fun learning techniques for the accelerating 21 st Century venues. Oddly enough, the use of "sacred" sound in the form of repetitions, mantras, zikrs, and affirmations go far back, historically, to ancient neurophysiological powers of chanting to reorganize the nervous system, and center consciousness---providing pathways to real learning by the deeper self.

Our exploration yielded possible quantitative and qualitative toy and robotic research as well as innovations to ponder, which we would like to share with you in our exploding state-of-the-art agenda--on the brink of voice recognition, ambiguous choice making, emotional mood factors and interacting motor and sensory capability--the hidden agenda of the rooster who shows his favorite hen an ostrich egg---"It's not that I'm complaining, mind you. It's just that I'd like you to see what others are doing!"

\section{References}

1. Andrews, T.G. and L.J. Cronbach, "Transfer of Training," Readings in Psychology of Learning [Ed, J. Tobias] the City College, New York, 1963.

2. Bancroft, Jane, "the Lazanov Language Class," Journal of Suggestive-Accelerative Learning \& Teaching, Society for Accelerated Learning and Teaching (S.A.L.T.), Vol.1, \#1, Spring, 1976.

3. - "Caycedo's Sophrology \& Lazanov's Suggestology---Mirror Images of a System." ERIC documents on Foreign Language Teaching \& Linguistic, 1979.

4. $\quad$ Carvajal, D., "Northrop Execs Play Bard Card to Motivate." The New York Times, Dec, 27, 1999.

5. $\quad$ Comaford, C., "Is Instructor-Led Training Dead?" PC Week, Feb.10, 1997, V14 N6 P58.

6. Emling, Shelly, "Command Performance: Increasingly Functional, Robots Poised as Next Must-Have Item," The Palm Beach Post, page 4F, 22 April 2001. 
7. Galvez-Martin, M., "Changing Teachers' Perceptions By Helping Students Learn Social Studies with Toys Through Play," (Ed. Hans. E. Klein,) Creative Teaching, Act 2.

8. $\quad$ Glasser, Wm., Control Theory, Harper \& Row: New York, 1984.

9. Holstein, W. K., \& W.R. Soukup, "Monte Carlo Simulation," Institute for Quantitative Research and Economics in Management, 23, Purdue University, Lafayette, IN, 1962.

10. Jonas, Gerald, Visceral Learning: Toward A Science Of Self-Control. Viking Press: N Y, 1973.

11. Judy, R.W. \& J. B. Levine, A New Tool For Educational Administrators: Educational Efficiency Through Simulation Analysis, University Of Toronto: Canada, 1987.

12. Lazanov, G. Suggestology \& Suggestopedia, Sofia, Bulgaria, Institute of Suggestology, 1969. [in Bulgarian]

13. $\quad$ Li-Ron, Yael, "Ready for the Future?" Newsweek, 30 October 2000, pp 10-14.

14. McKenzie, M.N., "For Today’s M.B.A.s, A Serious Bit of Levity,” The N Y Times, Feb.23, 1997.

15. O’Brien, T., Teaching Fundamental Aspects of Science Toys, School Sciences and Mathematics, (4), pp.203-207, 1993.

16. Ostraner, S. \& Lynn Schroeder, "Misson Control Center For The Mind," Psychic Discoveries Behind The Iron Curtain, Bantam Books (Prentice Hall): Englewood Cliffs, NJ 1970.

17. _ with Nancy Ostrander, Super-Learning 2000, Delacorte Press: New York, 1994.

18. Selman, V., \& M. Luzuringa, "Use Of Learning Aids In Teaching Quantitative Courses," 1990 Teacher's Conference, The American University, Washington, DC, January 20, 1990.

19. Shlain, Leonard. Art \& Physics: Parallel Visions in Space, Time and Light, (Quill), William Morrow: New York, 1991.

20. Steinberg, Jacque, "Visual Play's The Thing: Teacher Uses Cartoons To Win Converts To Shakespeare," The New York Times, 10 May 1998.

21. Tashev, T. \& T. Nathan, "Suggestology", Bulgaria Today, No .9, 1966.

22. Thro, Ellen, Robotics: The Marriage of Computers and Machines. Facts On File, Inc. New York, NY 1993.

23. Toffler, Alvin, The Third Wave, William Morrow: New York, 1980.

24. Young, Jeffrey R., "MIT Scholar brings Legos into the Digital Age." Chronicle of Higher Education, Nov.14, 1997, Washington, DC.

\section{Appendix A \\ Selman's M-E-D-I-C-A-S-A Model}

The MEDICASA Model is most effective for providing the necessary insights for further inventiveness, creativity and interdisciplinary usage, focusing on the development of learning aids for specific applications, and for preparing instructional goals and educational objectives [7]. : Abacus-type counters and Quincunx are demonstrated for concept integration. [Colored balls simulate defectives for control-charts.]

Measurement. This Quality Control Dilemma has students using micrometer calipers to measure thickness of foilwrapped candy, and computing the Average, the Standard Deviation and the Distribution.

Efficacy. This is the degree of higher-level integration of the unique concepts into the memory convolutions of the total brain.

Data Development. Students plot data points for statistical control limits for samples of, say, five; and for the total expected mean and dispersion [Standard Deviation].

Imagery \& Integration. Three-dimensional learning aids are integrated into the learning process for enhanced visualization and retention.

Computerization. Measured data, as well as estimated values, are fed into a graphical software package [1] for plotting statistical control limits and simulation experiments.

Analysis. Comparisons are made of computer outputs with hand-calculations. For clarification, students perform data evaluation, forecasts, caveats, rationales for disparities---in a dynamic format.

Sensitivity. Using simulation techniques, "what if?" questions are raised regarding basics.

Applicability. Radiational aspects of lessons learned for application to other educational venues. 


\section{Appendix B Typical Lazanov Lesson [French] Using Suggestology}

In a typical classroom at the institute [suggestology \& parapsychology], twelve people--students, house-wives, laborers, professionals, old and young--relax in reclining chairs that resemble airplane seats. The room looks more like a lounge than a classroom. The lighting is subdued to enhance the calming effect. The group is listening to music, gentle soothing music. They look as if they were at a concert, completely wrapped up in the harmony of symphonic sounds. Against the background of Brahms or Beethoven, the voice of the mentor seems somewhat businesslike, or if ordering work to be done, sometimes soft and calming, then unexpectedly hard, commanding. Her voice repeats in a special rhythm, on a special scale of intonation, French word, idioms, and their translation. But the students are not really listening. They have been warned not to pay attention, not to think about whether they hear the teacher. Relax. Do not think about anything. Their conscious minds are to be totally occupied by the music. The next day surprised students discover that even though they we sure they had learned nothing, they remember and can easily read, write and speak from 120 to 150 new words absorbed during the two-hour session. In the same way the toughest part of the language course, the grammar rules, painlessly take root in the minds of musiclulled students. Within a month students with no prior knowledge of a language have accepted two to three thousand vocabulary words and have a good grasp of the grammar. Longitudinal tests a year later show they still know all the material learned in this incredibly effortless way [6]. Classes run four hours a day: two hours for the suggestion session, one hour for the practice and tests, one hour for new material. Students come six days a week for three months. At the end of that time they have the equivalent of a two- or three-year course, a 6,000-word vocabulary, and a complete grasp of grammar. They can read, write and speak fluently.

Notes 
Notes 